\title{
Design and Performance Evaluation of a Sustained Load Dual Grip Creep Testing Machine
}

\author{
Kenneth Kanayo Alaneme ${ }^{1,2 *}$, Bethel Jeremiah Bamike1, Godwin Omlenyi ${ }^{1}$ \\ ${ }^{1}$ Department of Metallurgical and Materials Engineering, Federal University of Technology, Akure, Nigeria \\ ${ }^{2}$ Department of Mining and Metallurgical Engineering, University of Namibia, Ongwediva Engineering Campus, \\ Ongwediva, Namibia \\ Email: ${ }^{*}$ Kalanemek@yahoo.co.uk
}

Academic Editor: Joseph O. Borode, Federal University of Technology, Nigeria

Received 21 August 2014; revised 10 October 2014; accepted 21 October 2014

Copyright (C) 2014 by authors and Scientific Research Publishing Inc.

This work is licensed under the Creative Commons Attribution International License (CC BY).

http://creativecommons.org/licenses/by/4.0/

(c) () Open Access

\begin{abstract}
The design and performance evaluation of a sustained load creep testing machine was undertaken in this research. The design was motivated by the need to make locally available, a cost effective, technically efficient, and easily operated creep testing facility; for creep behaviour studies of materials. Design drawings and purchase of materials and components for the design were undertaken after thorough evaluation of the following design and materials selection criteria: design principle and theory, local availability of raw materials and components required for the design, material properties, cost of materials and design, ease of utilization and maintenance, and basis of testing and data capture. The machine casing and frame, heating chamber (consisting of the furnace and a dual specimen mounting stage), load lever and hanger system, and the electro-technical components; were fabricated and coupled following the produced design specifications. The machine was tested and its performance was assessed using its heating efficiency, repeatability and reproducibity of experimental test results, maintainability and cost-effectiveness as criteria. It was observed from repeat tests that the machine has the capacity of generating reliable data for computing creep strain-time results. The efficiency and temperature regulating capacity of the heating unit of the machine were also observed to be very satisfactory. The cost of the design was about 112,000 Naira $(\$ 700.00)$ which is cheaper in comparison to similar commercial creep testing machines from abroad. The machine was also found not to pose maintenance or repairs challenges.
\end{abstract}

\section{Keywords}

Creep, Failure Analysis, Machine Design, Strain Rate, Sustained Load Fracture 


\section{Introduction}

Creep has been acknowledged to be the most active failure mechanism of engineering materials under stress at elevated temperature conditions [1]. The considerable material flow which occurs over a period of time in creep situations can have grave material performance and service life implications [2]. Thus there is a lot of interest in understanding the creep behaviour of materials for high temperature applications. From a mechanical behaviour of materials perspective, creep mechanism is influenced by the increased atom mobility, vacancy density, and ease of dislocation glide or climb at elevated temperature [3] [4]. These phenomena often combine to facilitate permanent deformation which results in material rupture in severe creep cases [4].

Creep failure of components/parts in many industries such as metallurgical processing, power generation, petrochemical, spacecraft, and nuclear plants has been well reported in literature [5] [6]. In architectural and building designs, a good number of polymer/polymer composite materials are currently used as structural and semi-structural components. Due to exposure to intermittent solar radiation, the creep behaviour of these polymer based materials has also come under scrutiny [7]. It is thus imperative in materials design for high temperature applications, to account for creep behaviour to safeguard against likely failure short of projected design life time.

The basis for creep testing of materials including the specifications of facilities, specimens, and testing procedures has been assessed over the years following recommendations in ASTM standard codes [8] [9]. Creep tests are essentially used to establish a suitable design stress for components for a specified time and at given temperature or for specifying a maximum permissible strain for maintaining functionality of components during its service life [9].

Majorly due to high cost of purchase and maintenance of test facilities and accessories for creep testing, there exists a paucity of researches on creep studies of the myriad of materials developed within Africa by most African material engineers. Efforts to evaluate the creep properties of these indigenously developed materials outside the shores of Africa, do not always attract much interest from potential host organizations. There is also the need to conserve foreign exchange and work towards technological self-reliance. This research work is an effort to address these problems through the design of a creep testing machine using locally sourced raw materials and components. The design concept for this creep testing machine is based on the application of a constant load from a cantilever type lever on specimens mounted in an enclosed heating chamber (furnace). Some of the potential benefits of the design are low cost, maintainability, accessibility, and adaptability for research and experimental demonstrations.

\section{Materials and Method}

\subsection{Materials}

The materials used for the design of the creep testing machine are: mild steel sheets, square steel pipes, porous refractory bricks, fire clay, Kaolin, Nichrome heating elements, K-type thermocouple, light Indicators, temperature controller, dial gauge, timer, round and flat Chuck Grips, and stainless steel rods, copper wire and plugs, dead weights, and weight hangers.

\subsection{Design Considerations}

At the conceptualization stage of producing a design for the creep testing machine, the factors considered were: the design principle and theory, local availability of potential materials required for the fabrication, material properties, cost of materials, simplicity of the design, ease of utilization and maintenance of the machine, and basis of generating required data. These factors were instructive in the development of the design of the creep machine (Figure 1). The main parts of the cantilever type sustained load creep testing machine are: the machine casing and frames, the heating unit (which consists of a furnace with an inbuilt specimen clamping/mounting system), the loading frame which consists of the loading beam and the load hanger (which serves as the anchor from which the applied load is transmitted to the test specimen), dial gauge (to measure the strain generated by the specimen during testing), timer (which is utilized to record the time to failure or attaining a maximum permissible strain on the specimen), the electro-technical devices (which consists of the temperature controller, thermocouple and the light indicators) to set and maintain the temperature in the heating unit of the machine, and dead weights utilized to apply predetermined loads on the test specimens. These components/parts of the 
creep machine are indicated in the design (Figure 1(b)) with the aid of the legends identified in Table 1.

\subsection{Design and Materials Selection Criteria}

\subsubsection{Machine Casing and Frame}

Mild steel sheets ( $2 \mathrm{~mm}$ thick) were selected for the design of the machine casings. The choice of mild steel was based on low cost of purchase, good strength, weldability, excellent formability, and availability. The steel casing houses all the components of the creep testing machine including: the heating chamber made up of the furnace and specimen mounting system, the electro-technical devices (temperature controller, thermocouple, and light indicators), and the loading system and platform. Steel square pipes (equally $2 \mathrm{~mm}$ thick), was selected for the construction of the support frames of the machine. The steel frames serves to support the entire weight of the creep testing system. It also gives rigidity and balance to the entire creep testing unit.

\subsubsection{Furnace Design}

Refractory bricks, clay and kaolin were selected as lining materials for the design of the heating unit of the machine. The choice of the materials was influenced by low cost considerations, local availability, high refractory properties, and low thermal conductivity.

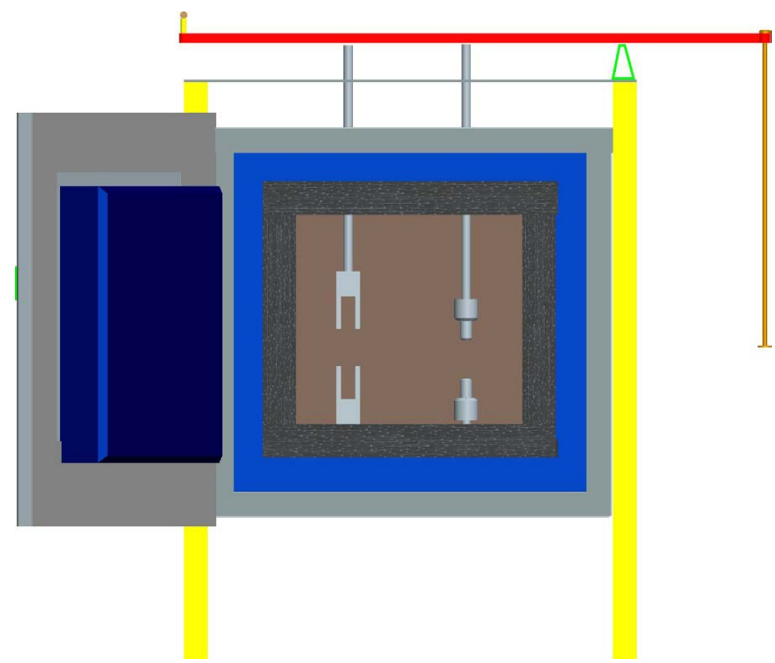

(a)

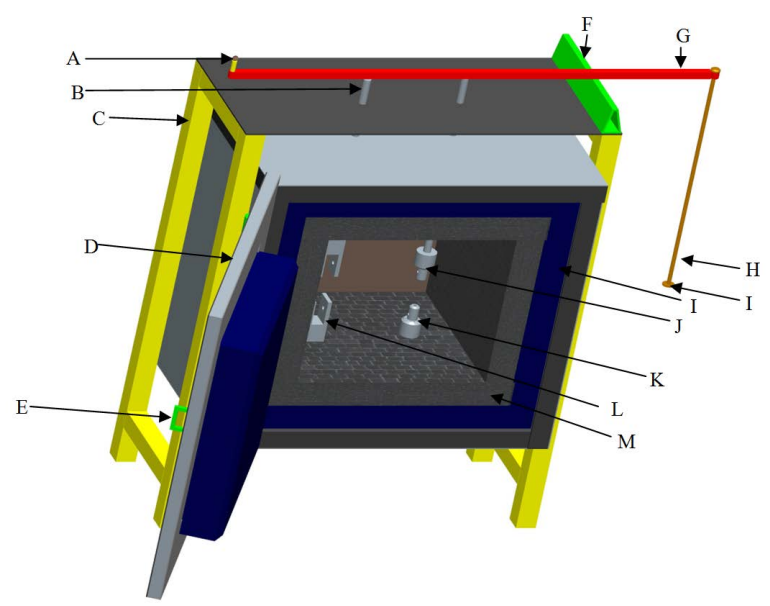

(b)

Figure 1. Showing modified: (a) Front view design of the creep testing machine; and (b) 3D full view design of the creep testing machine. 
Table 1. Legend of the 3D design of the creep testing machine presented in Figure 1(b).

\begin{tabular}{cc}
\hline Label & Name \\
\hline A & Dial Gauge \\
B & Grip Extension \\
C & Metal Frame \\
D & Furnace Door \\
E & Door Handle \\
F & Pivot \\
G & Lever \\
H & Load Pipe \\
I & Load Plate \\
J & Upper Circular Grip \\
K & Lower Circular Grip \\
L & Flat Grip \\
M & Refractory \\
\hline
\end{tabular}

\subsubsection{Clamps and Clamping System}

The clamping system of the machine consists of chuck grips needed to hold the test samples firmly in place during the creep experiments. Two different sample mounting platforms were designed having different grip configurations (one for cylindrical specimens while the other serves for flat specimens). This is to make it possible for different specimen configurations (flat and round) to be conveniently tested using either of the sample grip mounting platforms. The base of the mounting platforms is firmly bolted at the bottom of the casing of the heating chamber while the top end is flexibly connected to the load cantilever beam which is linked to the loading platform of the machine. The flexible connection allows for load applied through the load lever to be transmitted and sustained by the test sample only [10]. The chucks and connecting rods of both gripping systems (flat and round) were properly aligned and installed on the mounting stage of the machine. Chucks and pull rods made of high carbon low alloy steel (in the quenched and tempered condition) were selected for the design of the sample mounting system. Since the primary intent was basically to use the creep machine for low melting point light weight metallic materials and polymers; the creep resistance, thermomechanical fatigue resistance, oxidation resistance, high melting point, and relative low cost of the high carbon low alloy steel influenced its selection ahead of other competing materials.

\subsubsection{Cantilever Beam Loading System}

The loading system of the machine consists of a cantilever type load beam, a load hanger, and variable dead weights. Quenched and tempered high carbon low alloy steel materials were selected for the design of the load beam and load hanger. This is to ensure that the load frame possesses high strength, elastic modulus and rigidity; and is able to sustain the applied load over a long period of time without undergoing plastic deformation (bending) or fracture while in use [11]. This safeguards against potential erroneous strain capture by the dial gauge from the deformation of the load beam or load hanger as against that of the sample. The dimensions of the loading frame were carefully selected so that the weight of the loading frame does not add significantly to the weight acting on the test specimen as this could affect the calculated stresses acting on the specimen.

\subsubsection{Strain Measuring Device}

A dial gauge with measurement sensitivity of $0.001 \mathrm{~mm}$ was selected as strain recording device. It is connected at the opposite arm of the loading point of the cantilever beam so as to capture changes in the strain of the test sample. When load is applied to the specimen, strain occurs and relative movement between the gripping points is transmitted through the load beam to the dial gauge. A portable precision hour-minute-second timer was selected to monitor the time dependence of the strains developed on the specimens. 


\subsubsection{Electro-Technical System}

The electro-technical system consists of the temperature controller, the heating elements, the thermocouple, and the light indicators. A Nichrome coil was selected as heating element for the furnace. Nichrome was selected as resistance heating element for the furnace because it efficiently converts electricity into heat. It possesses good ductility and formability-requirements needed to form it into coils of any shape and size. It also has a relatively high melting point, can maintain its original shape and dimensional integrity even after several heating cycles, and has a high oxidation resistance [12]. The temperature controller selected as part of the electro-technical devices has the capacity of sensing fractions of temperature which helps in improving the precision and accuracy of the readings sensed by the thermocouple during the operation of the furnace. The connection of the electrotechnical devices (temperature controller, thermocouple and the light indicators) help to set, regulate and monitor the temperature in the heating unit of the machine to ensure it is within acceptable limits of the set value (target temperature).

\subsection{Fabrication Procedure}

The casing for the heating chamber was first positioned and lined with refractory bricks and then plastered using a mixture of kaolin, clay, and water which served as binder in accordance with Alaneme et al. [13]. Grooves were created around the lined refractory bricks for the housing of the heating elements. The heating elements were passed through the grooves to allow for efficient and even heat generation. The gripping devices for the mounting of the specimens for testing were then positioned within the chamber with the bottom end bolted firmly at the base of the heating chamber (fixed end) and the top portion of the gripping system connected to the movable load lever system with the help of a hinge [14]. The furnace was then covered at the top with bricks and a metallic sheet and the moveable part of the grips (upper grips) were held in place. The electrical connection to the heating element was done and linked to the electro-technical devices which were placed in a steel box casing by the side of the heating chamber. The assembly of the electro-technical devices in its housing required the connection of the thermocouple through the thermocouple lead to the temperature controller. The heating chamber (furnace) is powered through an industrial switch linked to an AC power source. The progression in heating measured by temperature is monitored with the help of the LED light indicator and temperature controller display. On completion of the assembly of the various components of the machine, it was cleaned using emery papers to obtain a smooth finish and then sprayed to improve the finishing. The interior view of the heating chamber and the external view of the fabricated machine are presented in Figure 2.

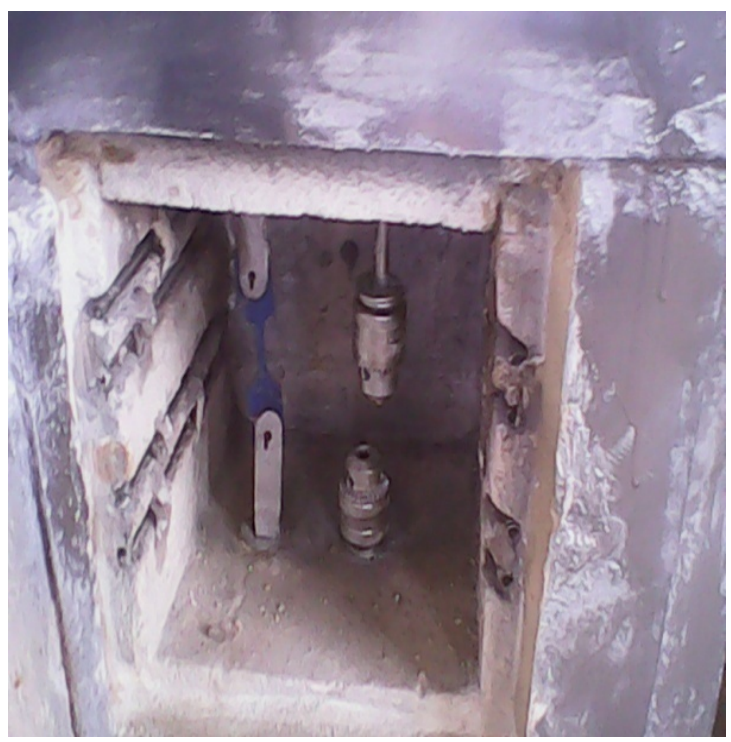

(a)

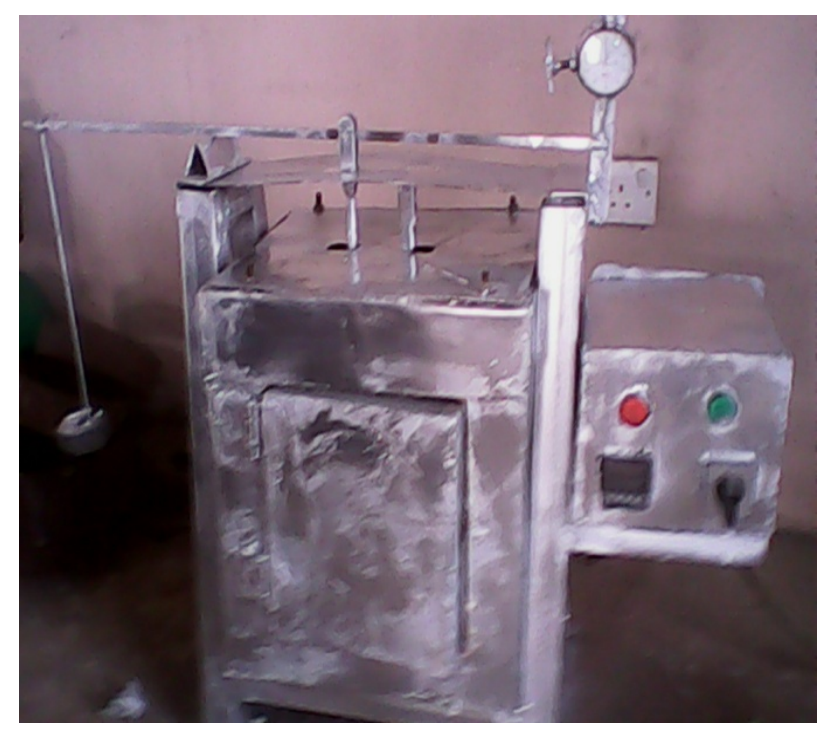

(b)

Figure 2. Showing (a) completed interior view of the creep testing machine and (b) complete full exterior view of the creep testing machine. 


\subsection{Testing of the Machine}

A number of polymer based materials, polypropylene/polypropylene based composites and polytetra fluoroethylene (pictured in Figure 3) were selected as test material for assessing the operation of the machine. The flat test samples were machined having gauge length of $40 \mathrm{~mm}$ and $2 \mathrm{~mm}$ thickness, and tested following specifications of the ASTM D2990-09 standard [8]. The machined test sample was mounted on the chucks of the machine, before the furnace is switched on and the desired temperature set on the temperature controller. A known weight is applied on the specimen through the load hanger and to ensure accuracy of the readings from the test, the dial gauge is set at zero for accurate extension capture. The timer is equally switched on to assist the recording of extension values at specified time intervals. The specimen strain at the specified time intervals is determined by dividing the sample extension by the original gauge length of the sample. Several repeat tests were performed to ascertain the consistency in results obtained under same test conditions.

\section{Results and Discussion}

\subsection{Machine Performance}

The consistency of repeat test results obtained from the testing of samples showed that the machine can be used to generate reliable strain-exposure time data needed for studying the creep behaviour of materials. Representative results from creep testing of polyfluoroethylene (Figure 4) is observed to follow the characteristic creep deformation sequence and the creep strain rate increases with applied stress at a constant temperature $\left(100^{\circ} \mathrm{C}\right)$
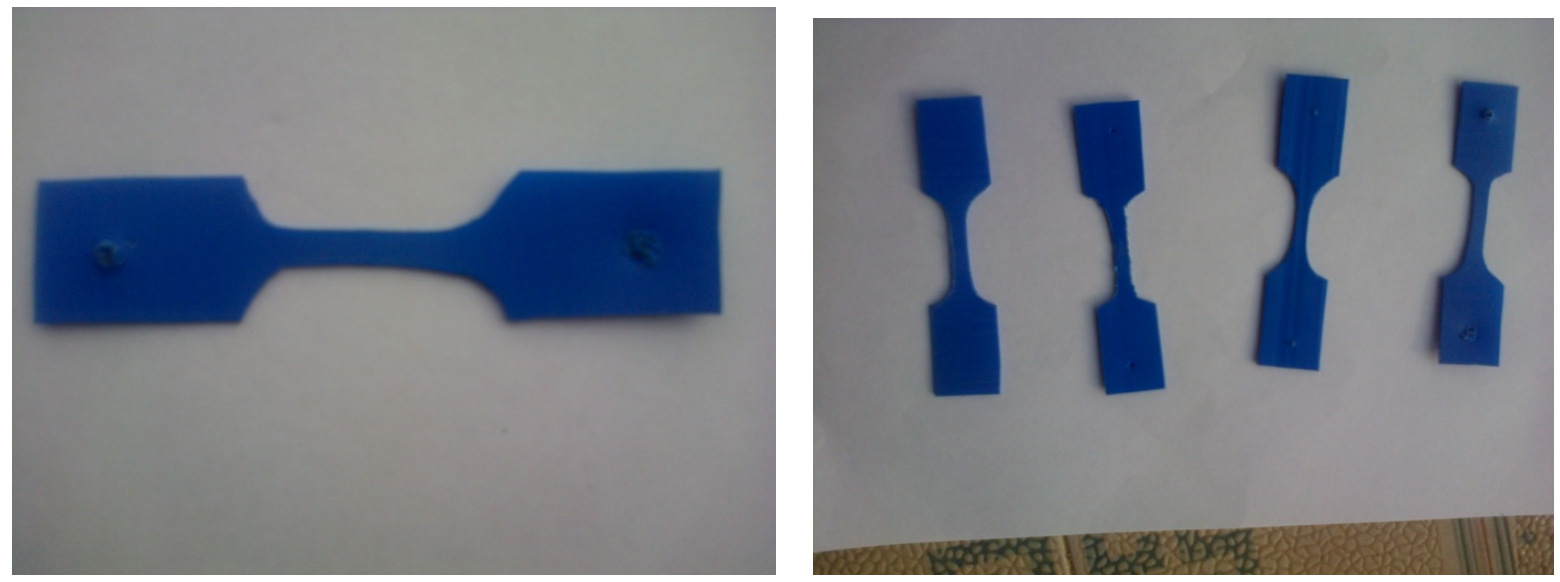

Figure 3. Representative test samples of polytetrafluoroethylene (Teflon) used for Creep Testing.

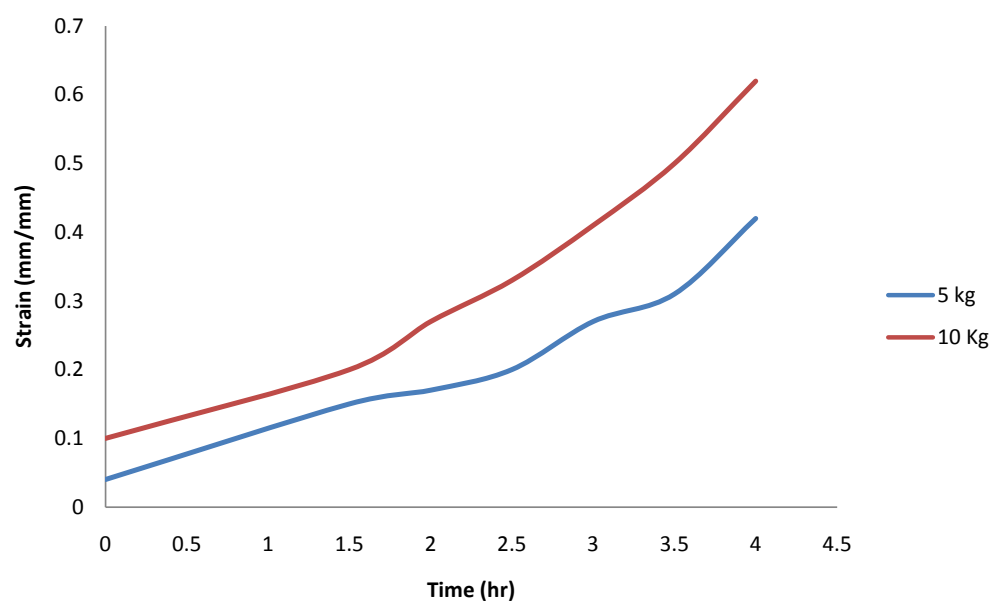

Figure 4. Representative creep strain versus time plots for Polytetrafluoroethylene (Teflon) at different applied load at constant temperature of $100^{\circ} \mathrm{C}$. 
[2]. The creep behaviour observed from the test material (polyfluoroethylene) is comparable with creep characteristics of similar materials reported in literature [15]. It was also observed that the furnace has a high heating rate and is able to maintain a set temperature value at an accuracy of $\pm 2^{\circ} \mathrm{C}$. The furnace had good heat retaining capacity an indication that the refractory selected has good refractory properties and the lining of the furnace was properly done leaving little room for heat losses [16].

The machine function was optimized by careful application of some operational strategies especially with the heating unit which is the automated part of the machine. The thermocouple tip is positioned close to the position of the gripping system where the specimens are mounted to ensure that the temperature of the specimen is at the set point temperature value and not just the temperature of the furnace environment that is sensed. Regular calibration of the temperature controller using an external probe is performed to ensure reliability of the temperature readings obtained from the furnace. When testing is to be performed thorough care is taken to ensure that the specimens are tightly clamped in the chuck to safeguard against removal of specimen when the machine is in operation. It was also ensured that the whole machine set up was securely fasted to the machine frame to ensure safety of operator and machine during testing. The mode of operation of the machine can be easily comprehended and does not require complicated basis for data recording. In the case of machine malfunction, the design was made such that all parts can be easily detached and repaired. The replacement of any of the machine parts and fabrication materials when required can be done easily as all parts used in the design of the machine are relatively cheap and can be sourced locally.

\subsection{Cost Analysis}

The entire materials and components used for the design of the creep testing machine are presented in Table 2. The materials and equipment used in the design are locally sourced, and the overall cost of designing the machine is approximately 112,000 Naira $(\$ 700.00)$. The machine is obviously cheaper in comparison to similar commercial brands of creep testing machines designed abroad.

\section{Conclusion}

The design and performance evaluation of a creep testing machine was investigated. The design was motivated

Table 2. Bill for engineering management and evaluation.

\begin{tabular}{|c|c|c|c|c|c|}
\hline $\mathrm{S} / \mathrm{N}$ & Material & Specification & Quantity & Unit Cost ( $($ ) & Amount (N) \\
\hline 1 & Porous Bricks & Insulating & 20 & 750 & 15,000 \\
\hline 2 & Heating Element (Nichrome) & $220-240 \mathrm{~V}, 2 \mathrm{KW}$ & 2 & & 33,000 \\
\hline 3 & Jaw Chuck & & 2 & 1,500 & 3000 \\
\hline 3 & Bits (15 mm Diameter) & & 1 & 1,200 & 1200 \\
\hline 4 & Contactor & 40 Amp & 1 & 2,500 & 2500 \\
\hline 5 & Thermometer & $1200^{\circ} \mathrm{C}$ & 1 & 8,000 & 8000 \\
\hline 6 & Thermocouple & K-type & 1 & 2,000 & 2000 \\
\hline 7 & Sheet Metal & $2 \mathrm{~mm}$ thick & 0.5 & 3,000 & 3000 \\
\hline 8 & Square Pipe & $2 \mathrm{~mm}$ thick & 2 & 2,000 & 4000 \\
\hline 9 & Copper Cable & OFHC & & 700 & 1200 \\
\hline 10 & Dial Gauge & Calibrated & 1 & 5,000 & 5000 \\
\hline 11 & Painting & Oil paint & 2 litres & & 1000 \\
\hline 12 & Transportation/Logistics & & & & 12,000 \\
\hline 13 & Labour & & & & 20,000 \\
\hline 14 & Total & & & & 110,900 \\
\hline
\end{tabular}


by the need to make locally available, a cost effective, technically efficient, and easily operated creep testing facility; for creep behaviour studies of materials. On testing and assessing the performance of the machine, it was observed from repeat tests that the machine has the capacity of generating reliable data for computing creep strain-time results. The efficiency and temperature regulating capacity of the heating unit of the machine were also observed to be very satisfactory. The cost of the design was about 112,000 Naira $(\$ 700.00)$ which is cheaper in comparison to similar commercial creep testing machines from abroad. The machine was also found not to pose maintenance or repairs challenges.

\section{References}

[1] Rosler, J., Harders, H. and Baker, M. (2007) Mechanical Behaviour of Engineering Materials-Metals, Ceramics, Polymers, and Composites. Springer, Germany, 333-375.

[2] Soboyejo, W. (2002) Mechanical Property of Materials. Princeton University, Princeton, 468-480.

[3] Naumenko, K. and Altenbach, H. (2007) Modeling of Creep for Structural Analysis. Springer, New York. http://dx.doi.org/10.1007/978-3-540-70839-1

[4] Dieter, G.E. (1986) Mechanical Metallurgy. 3rd Edition, McGraw-Hill, New York.

[5] Ravi, S., Laha, K., Sakthy, S., Mathew, M.D. and Jayakumar, T. (2014) Design of Creep Machine and Creep Specimen Chamber for Carrying out Creep Tests in Flowing Liquid Sodium. Nuclear Engineering and Design, 267, 1-9. http://dx.doi.org/10.1016/j.nucengdes.2013.10.020

[6] Evans, R.W. and Wilshire, B. (1993) Introduction to Creep. The Institute of Materials, London, 1-75.

[7] Kawai, M. (2001) Off-Axis Creep Behavior of Unidirectional Polymer Matrix Composites at High Temperature. Solid Mechanics and its Applications, 86, 469-478.

[8] ASTM D2990-09 (2009) Standard test Methods for Tensile, Compressive, and Flexural Creep and Creep Rupture of Plastics. Annual Book of ASTM Standards, ASTM International, West Conshohocken.

[9] ASTM E139-11 (2011) Standard Method for Conducting Creep, Creep-Rupture, and Stress-Rupture Tests of Metallic Materials, Annual Book of ASTM Standards, ASTM International, West Conshohocken.

[10] Alaneme, K.K. (2011) Design of a Cantilever-Type Rotating Bending Fatigue Testing Machine. Journal of Minerals \& Materials Characterization \& Engineering, 10, 1027-1039.

[11] Alaneme, K.K. (2011) Development of a Cantilever Beam-Sustained Load Stress Corrosion Testing Rig. Journal of Metallurgy and Materials Engineering, 6, 22-26.

[12] Srivasta, S. (2014) Properties of Nichrome Wire. http://www.buzzle.com/articles/properties-of-nichrome-wire.html

[13] Alaneme, K.K., Olanrewaju, S.O. and Bodunrin, M.O. (2011) Development and Performance Evaluation of a Salt Bath Furnace. International Journal of Mechanical and Materials Engineering, 6, 67-74.

[14] Momoh, J.J., Shuaib-Babata, L.Y. and Adelegan, G.O. (2010) Modification and Performance Evaluation of a Low Cost Electro-Mechanically Operated Creep Testing Machine. Leonardo Journal of Science, 16, 83-94.

[15] Sakai, T. and Somiya, S. (2011) Analysis of Creep Behavior in Thermoplastics Based on Visco-Elastic Theory. Mechanics of Time-Dependent Materials, 15, 293-308. http://dx.doi.org/10.1007/s11043-011-9136-y

[16] Alaneme, K.K. and Olanrewaju, S.O. (2010) Design of a Diesel Fired Heat-Treatment Furnace. Journal of Minerals and Materials Characterization and Engineering, 9, 581-591. 
Scientific Research Publishing (SCIRP) is one of the largest Open Access journal publishers. It is currently publishing more than 200 open access, online, peer-reviewed journals covering a wide range of academic disciplines. SCIRP serves the worldwide academic communities and contributes to the progress and application of science with its publication.

Other selected journals from SCIRP are listed as below. Submit your manuscript to us via either submit@scirp.org or Online Submission Portal.
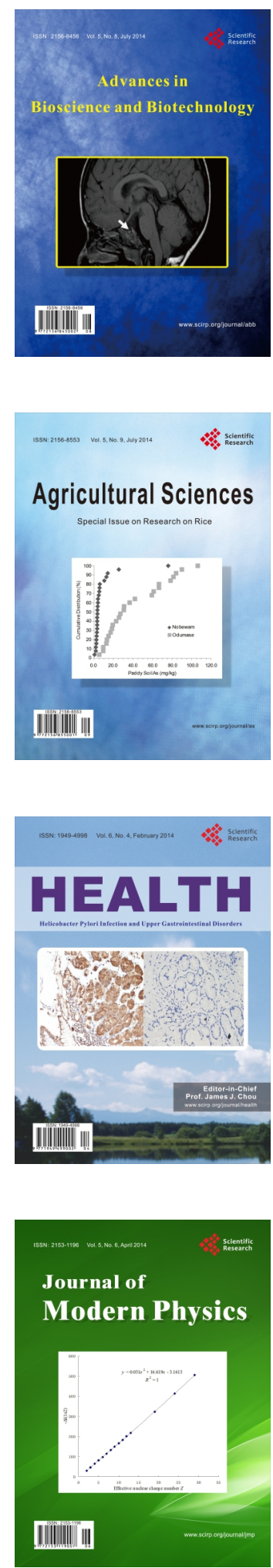
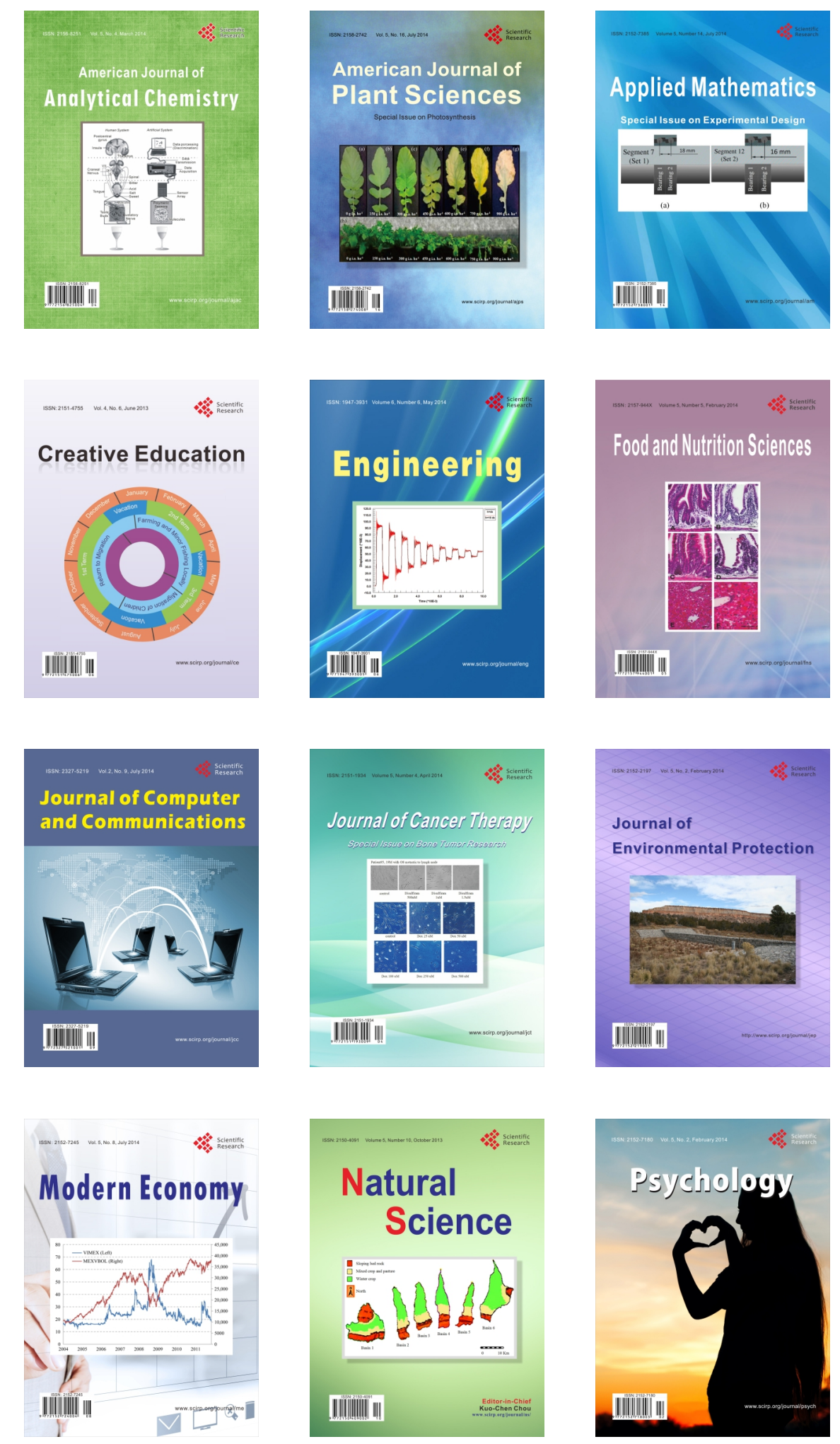